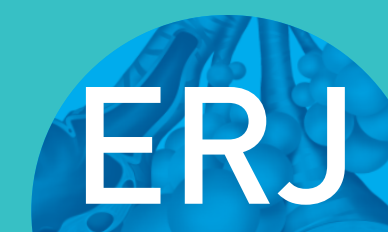

open research
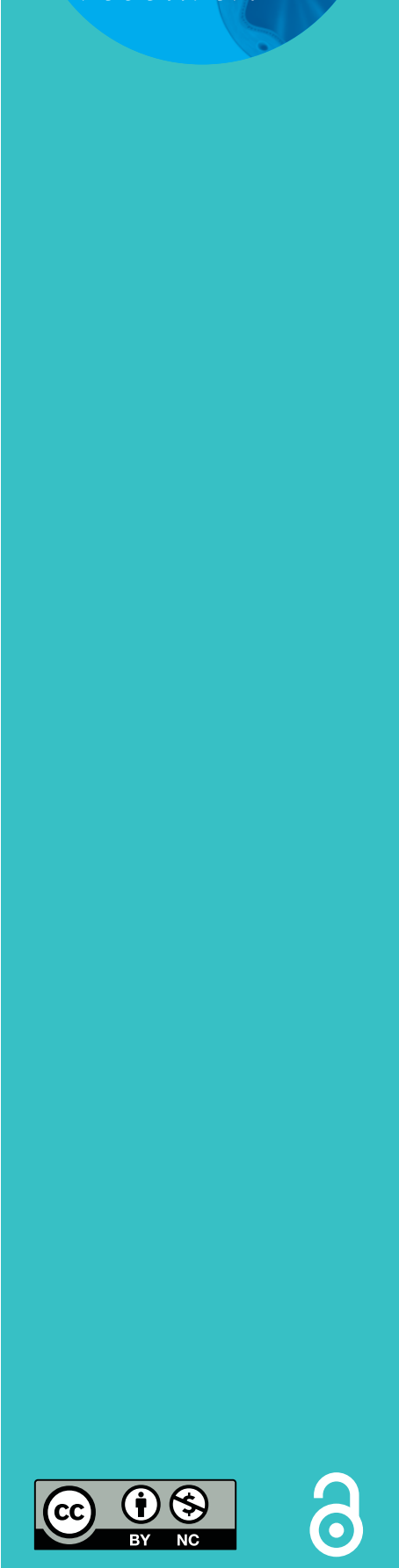

\section{Key paediatric messages from the 2016 European Respiratory Society International Congress}

\author{
Jonathan Grigg ${ }^{1}$, Ian M. Balfour-Lynn², Mark Everard ${ }^{3}$, Graham Hall ${ }^{4}$, \\ Bülent Karadag ${ }^{5}$, Kostas Priftis ${ }^{6}$, Charles Christoph Roehr ${ }^{7}$, Bart L. Rottier ${ }^{8}$ and \\ Fabio Midulla ${ }^{9}$
}

\begin{abstract}
Affiliations: ${ }^{1}$ Centre for Paediatrics, The Blizard Institute, Queen Mary University of London, London, UK. ${ }^{2}$ Dept of Paediatric Respiratory Medicine, Royal Brompton Hospital, London, UK. ${ }^{3}$ Princess Margaret Hospital for Children School of Paediatric and Child Health, University of Western Australia, Perth, Australia. ${ }^{4}$ Telethon Kids Institute, Subiaco, Australia. ${ }^{5}$ Dept of Paediatrics, Athens University Medical School, Attikon General Hospital, Athens, Greece. ${ }^{6}$ Division of Pediatric Pulmonology, Marmara University, School of Medicine, Istanbul, Turkey. ${ }^{7}$ Dept of Paediatrics, Newborn Services, John Radcliffe Hospital, Oxford University Hospitals NHS Foundation Trust, Oxford, UK. ${ }^{8}$ Dept of Paediatric Respiratory Medicine, Groningen Research Institute of Asthma and COPD, University Medical Center Groningen, Beatrix Childrens' Hospital, State University Groningen, Groningen, Netherlands. ${ }^{9}$ Dept of Paediatrics, Sapienza University of Rome, Rome, Italy.
\end{abstract}

Correspondence: Jonathan Grigg, Centre for Paediatrics, The Blizard Institute, Queen Mary University of London, 4 Newark Street, London, E12AT, UK. E-mail: j.grigg@aqmul.ac.uk

ABSTRACT In this article, the Group Chairs of the Paediatric Assembly of the European Respiratory Society (ERS) highlight some of the most interesting abstracts presented at the 2016 ERS International Congress, which was held in London.

@ERSpublications

Highlights of the most interesting paediatric research abstracts presented at the 2016 ERS International Congress http://ow.ly/rTfB3075cPQ

Cite this article as: Grigg J, Balfour-Lynn IM, Everard M, et al. Key paediatric messages from the 2016 European Respiratory Society International Congress. ERJ Open Res 2017; 3: 00127-2016 [https://doi.org/10.1183/23120541.00127-2016].

Received: Nov 162016 | Accepted after revision: Dec 072016

Support statement: J. Grigg was funded in part by the Dept of Health, National Institute for Health Research (Programme Grants for Applied Research, North Thames CLAHRC). Funding information for this article has been deposited with the Open Funder Registry.

Conflict of interest: Disclosures can be found alongside this article at openres.ersjournals.com

Copyright $\odot$ ERS 2017. This article is open access and distributed under the terms of the Creative Commons Attribution Non-Commercial Licence 4.0. 


\section{Introduction}

Paediatric respiratory medicine is recognised as an important separate track at the European Respiratory Society (ERS) International Congress. In this article, the Group Chairs of the ERS Paediatric Assembly highlight some of the most interesting abstracts in infection, intensive care, bronchology, cystic fibrosis (CF), physiology, sleep medicine and asthma that were presented at the 2016 ERS International Congress.

\section{Infection}

Over recent years the widely held belief that the lower airways were in some way uniquely sterile has been overturned with a general recognition that there is a resident microbiota which appears to be largely derived from the oropharynx. We have only a rudimentary understanding of the dynamics of these microbial populations but it is now recognised that the populations may change significantly during acute and chronic pulmonary disease. Data from the UK on the composition of the bacterial community in the airways of healthy children were presented. Samples were obtained using "blind" bronchial brushings, and compared with those present in the airways of children with recurrent or persistent bacterial bronchitis (PBB) undergoing bronchoscopy [1]. Data were generated using 16s RNA sequencing. Paired "blind" brushings and bronchoscopically guided brushings were obtained from the symptomatic children, with the results generated using "blind" brushings obtained via endotracheal tubes reflecting those obtained bronchoscopically, suggesting this is a valid approach to study lower airways microbial populations. As might be predicted, the density of bacteria in the symptomatic children did not differ significantly from that in the healthy children but the diversity was significantly reduced, possibly reflecting the formation of biofilms that permit the usual suspects to come to dominate this particular ecological niche (figure 1). The chronic neutrophilic inflammatory response characteristic of $\mathrm{PBB}$ is thought to result in airways damage and eventually the formation of bronchiectasis if it is not cleared by the host or is not treated effectively. Unsurprisingly, loss of diversity within the bacterial community contained in sputum from HIV-infected children with established bronchiectasis was the principle finding from a study undertaken in South Africa [2]. In this case, the control group were children with CF from previous studies who might be expected to manifest a loss of diversity when compared with healthy individuals, highlighting the magnitude of the changes in the HIV bronchiectasis group. The clinical importance of PBB was presented by GrammEniaTis et al. [3], who found that $40(56.3 \%)$ out of 71 children with PBB were symptom free for 12 months after treatment of varying duration (20.2 \pm 7.7 months) with a mean delay in diagnosis of $18.5 \pm 15.9$ months. In parallel with the advances being made in our understanding of microbial communities within the airways and gut as a player in health and disease, new "omics" technology in the form of either metabolomics or phenomics is starting to play an increasing role in research and indeed in clinical practice. Systems biology, integrating many of the novel technologies as well as traditional approaches, is likely to move into the mainstream in coming years. A presentation from a Taiwanese group of researchers presented data suggesting that $1 \mathrm{H}$-nuclear magnetic resonance spectroscopy, which is used to characterise the metabolomic profile of pleural fluid, is able to predict those in whom more aggressive intervention might be required [4]. The exact role metabolomics may play in diagnosis and monitoring in the future is yet to be determined.

Acute bronchiolitis continues to be one of the commonest causes for hospitalisation in infants and young children. Treatment has changed little over the past 50 years with good supportive care being key to management. A study addressing the potential role of high-flow oxygen as a means of improving supportive care undertaken in Newcastle, Australia, was presented with the authors concluding that the approach may offer significant benefits in terms of reducing the number of children reaching intensive care but had no impact on duration of oxygen therapy [5]. A theoretical health economic study suggested that this approach may be cost effective by reducing the costs associated with intensive care [6]. However, the latter group noted that there have not been large definitive prospective randomised clinical trials to support this position. The same group reported that only $0.25 \%$ of infants admitted with acute bronchiolitis required intensive care [7], while another group in a unit not using high flow as a form of respiratory support found 14\% required "high dependency" nursing but made no comment regarding intensive care usage [8]. A recent study retrospectively assessing a small number of "controls" suggested as many as $33 \%$ of infants might be admitted to paediatric intensive care and such discrepancies in local practice make assessment of small scale studies difficult [9]. A presentation assessing the impact of respiratory syncytial virus (RSV) monoclonal antibody levels in vitro concluded that re-activation of abortive RSV replication might occur spontaneously when antibody levels fall [10].

A Brazilian group reported outcomes in 21 children who developed necrotising pneumonia [11], a condition that appears to be becoming more common. Prolonged antibiotic therapy combined with drainage of the associated empyema present in the $81 \%$ of subjects with this finding resulted in an "excellent" outcome for all of the patients. Findings were consistent with previous reports. Differentiated nasal epithelial cells were used to explore potential differences in the inflammatory response of the airways epithelium in those with atopic asthma, non-atopic asthma and non-atopic controls in a study undertaken 


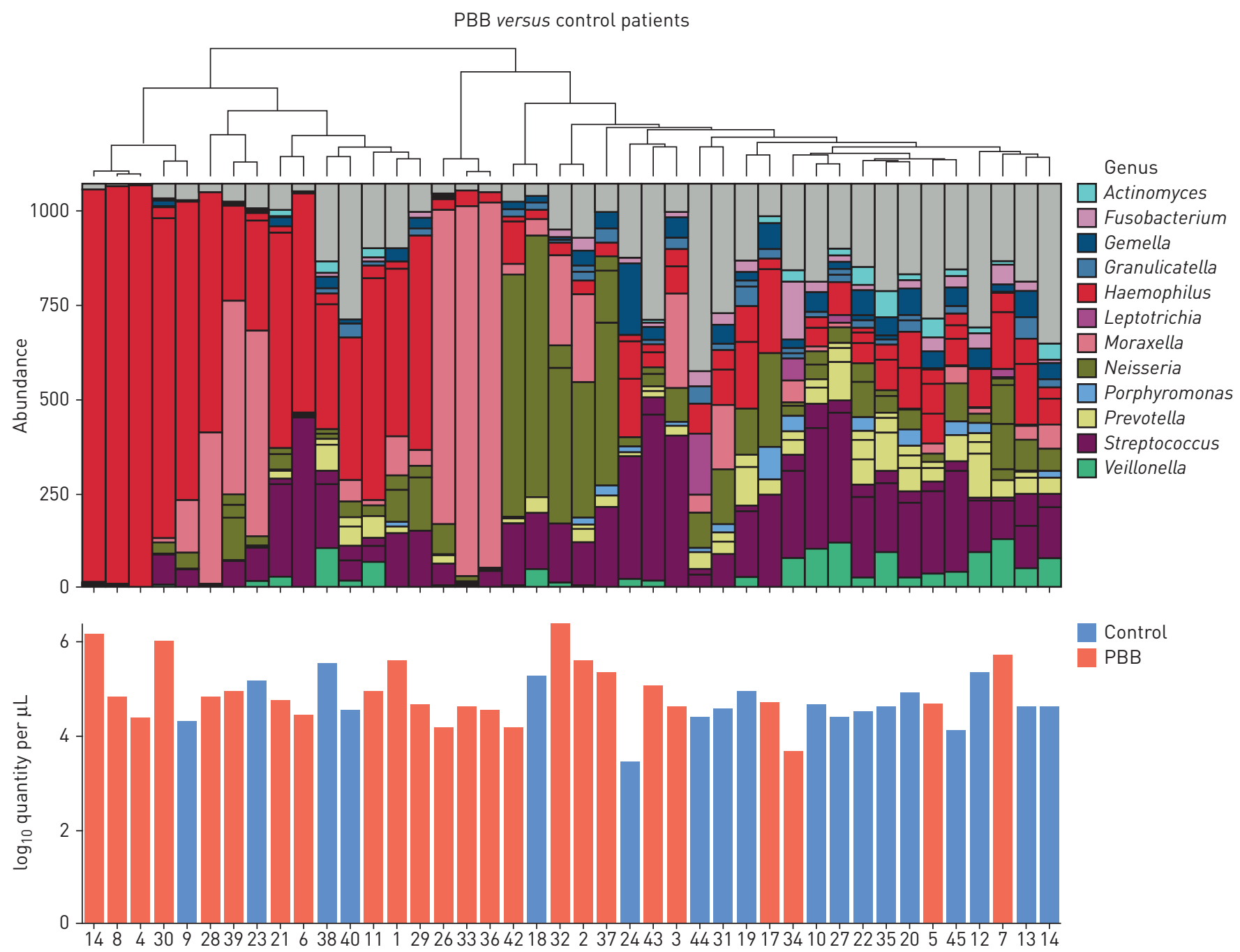

FIGURE 1 The pulmonary microbiome of children with persistent bacterial bronchitis (PBB). DNA was extracted from bronchial brushes of 24 PBB children and 18 healthy controls and 16S rRNA gene GPCR quantified the bacterial burden prior to sequencing. Permutational multivariate analysis of variance shows that total community dissimilarity is significantly different $\left(R^{2}=0.08, p=0.004\right)$ and indicator species analysis shows that Haemophilus is significantly associated with PBB. Reproduced from [1] with permission from the publisher.

in Scotland, UK [12]. The authors concluded that there are some aspects of the response in "asthmatic" epithelium (albeit from the nose) that is different from that attributable to "atopy". The difficulty with these studies of course is trying to untangle what might be innate and what may be secondary to the particular condition, particularly given the increasing knowledge around epigenetic changes.

\section{Intensive care}

Respiratory management of infants and young children has been an important area of research over the previous year. Hence, the 2016 ERS Congress addressed the important area of the very early physiological pulmonary adaptation to prevent infantile lung disease $[13,14]$, and the long-term outcomes of neonatal lung disease. HARRIs et al. [15] investigated the first breath during neonatal resuscitation with regards to applied inflation pressures and to characterise the factors associated with a shorter time to the first active inspiration in 47 infants aged $<34$ weeks gestation requiring resuscitation at birth. The authors found that the median time to the first active inflation was inversely correlated with the applied peak pressure $(\mathrm{p}=0.001)$ and inflation time $(\mathrm{p}=0.018)$ of the first active inflations. These observations support the concern that during preterm resuscitation too low an initial inflation pressure may delay pulmonary transition and indeed high initial pressures may be beneficial when supporting fetal-to-neonatal transition. Also investigating the initial respiratory support, KAMLIN et al. [16] examined optimising neonatal resuscitation in the delivery room by use of an Guedel oropharyngeal airway (OPA) in infants aged $<34$ weeks gestation. The assumption was that use of an OPA reduces airway obstruction, facilitates improved ventilation and improves clinical outcomes. Infants were studied in a two centre randomised 
controlled trial (RCT) and, following randomisation, managed using standard national guidelines and randomised to face mask (control) or mask plus OPA (intervention) positive pressure ventilation (PPV) provided by a T-piece resuscitator. Using a physiological data acquisition set to measure the incidence of complete (no gas flow) and partial airway obstruction, the authors reported that face mask obstruction was common during PPV and use of OPAs was associated with significantly higher rates of partial obstruction [16]. Working in the same environment (i.e. the delivery room), PAHUjA et al. [17] studied expiratory tidal volume $(V \mathrm{~T})$ and end-tidal carbon dioxide tension $\left(\mathrm{ETCO}_{2}\right)$ during resuscitation of prematurely born infants. The hypothesis was that prematurely born infants who developed intracranial haemorrhages or bronchopulmonary dysplasia (BPD) were given higher expiratory $V \mathrm{~T}\left(>6 \mathrm{~mL} \cdot \mathrm{kg}^{-1}\right)$ and/or had low $P \mathrm{ETCO}_{2}$ levels during resuscitation and stabilisation in the delivery room. Again, infants with a gestational age of $<34$ weeks were studied around the time of birth. Expiratory $V \mathrm{~T}$ and $\mathrm{PETCO}_{2}$ levels were simultaneously recorded using a respiratory function monitor. Of the 80 infants studied, 36 developed intracranial haemorrhages and 34 developed BPD. The authors found a greater number of inflations at birth with a high expiratory $V \mathrm{~T}$ ( $\mathrm{p}$ 0.001) and a low $\mathrm{PETCO}_{2}$ ( $\mathrm{p}$ 0.01) in the intracranial haemorrhage-affected infants, stressing the well-established point that hypocarbia is a significant risk factor for intracranial haemorrhages in neonates. Furthermore, their results emphasise how the use of a respiratory function monitor can be helpful in gauging resuscitative efforts during neonatal resuscitation and improve outcomes of prematurely born infants [18].

In the neonatal unit, continuous positive airway pressure (CPAP) and appropriately conditioned breathing gasses are the commonest method of choice for noninvasive respiratory support $[19,20]$. However, while clinical studies in adults suggest that mouth leaks impair gas conditioning during CPAP, similar data for neonates is lacking. In a bench top study, FISCHER et al. [19] studied the impact of mouth leaks on oropharyngeal temperature and humidity during neonatal CPAP. The authors found that during CPAP, mouth leaks impaired oropharyngeal gas conditioning significantly, but heated humidification maintained clinically acceptable humidity levels. The topic of ongoing respiratory support after initial stabilisation is a matter of continuing debate. High-flow nasal cannula therapy has recently been proposed as an alternative to nasal CPAP $[20,21]$. In their presentation, MAZMANYAN et al. [22] investigated the influence of nasal high-flow therapy via nasal cannula on the minute ventilation of newborn infants compared to controls (no respiratory support). Using respiratory inductance plethysmography, 17 newborn infants were monitored during $8 \mathrm{~L} \cdot \mathrm{min}^{-1}$ of high-flow nasal cannula therapy. Results were remarkable in as much as their ventilatory response during nasal high-flow therapy resulted in a significant reduction in minute ventilation $\left(0.664 \pm 0.207\right.$ to $\left.0.506 \pm 0.145 \mathrm{~L} \cdot \mathrm{min}^{-1} ; \mathrm{p}=0.0006\right)$, an effect previously only described in adult studies of nasal high-flow therapy. The trend for increased use of nasal high-flow therapy was reported in three posters presented at the Congress [23-25], with nasal high-flow therapy in neonates in UK neonatal intensive care units increasing from 56\% in 2012 to 90\% in 2015. Studies were also presented on refining invasive ventilation and use of advanced ventilator technology and software to optimise ventilator management. In an interesting study, BENTSEN et al. [26] investigated whether using flow data from a mechanical ventilator would be helpful in predicting the development of BPD in extremely preterm neonates. In this study, investigators aimed to investigate whether simple lung mechanics, obtained from flow data from a mechanical ventilator, could be used to predict BPD in extremely preterm infants. In 21 preterm neonates with a mean gestational age of 25.9 weeks, data from the first days of ventilation were gathered and analysed by specific software with respect to the flow at $50 \%$ exhaled volume as ratio of peak flow (F50) and the results correlated to the clinical outcome of BPD severity. Values for F50 were significantly higher in the moderate/severe BPD group, compared to no or mild BPD: 68.0 versus 84.4 $(\mathrm{p}=0.011)$. The study therefore suggests that data obtained from ventilators during early hours of life may help to predict later BPD in preterm neonates.

A number of contributions to the 2016 ERS Congress were related to the long-term outcome of BPD. Following up outcomes of preterm infants, HARRIs et al. [15] studied the impact of post-natal corticosteroids treatment of very premature infants on their lung function testing at school age. In a cohort of 244 ex-preterm, very low birth weight infants at 11-14 years of age, these researchers found that the subgroup of infants with BPD who had been exposed to post-natal corticosteroids had significantly reduced lung function values in their expired vital capacity (forced expiratory flow at $25 \%, 50 \%$ and $75 \%$ of forced vital capacity (FEF25, FEF50, FEF75), respectively), forced expiratory volume in $1 \mathrm{~s}$ (FEV1) and peak expiratory flow compared with unexposed infants with BPD. These results suggest that post-natal corticosteroids, administered to the sickest infants at the time of mechanical ventilation, may have long-term adverse effects on lung function. A late-breaking abstract by Moschino et al. [27], prospectively followed neonatal patients with BPD from infancy to adulthood. Data from the patient cohort first studied in 1991 and followed up until early 2016 was analysed to longitudinally investigate the evolution of lung function in neonatal intensive care unit survivors with BPD. A total of 17 patients with a birth weight $<1250 \mathrm{~g}$ who had moderate-to-severe BPD were subjected to regular lung function studies, including maximal flow at 
functional residual capacity at 2 years and FEV1, forced vital capacity and FEF25-75 at ages 9, 15, 20 and 24 years. Results confirmed the concept of "tracking" of lung function with consistent lung function tracking between 2 and 24 years of age in survivors of BPD [28]. Mean z-scores for forced vital capacity and FEF25-75 did not change significantly between different ages ( $p>0.5$ and $p=0.45$, respectively). Significant correlations were found between the $\mathrm{z}$-scores for maximal flow at functional residual capacity at 2 years and for FEV 1 at ages 15 years $(\mathrm{r}=0.74, \mathrm{p}=0.001), 20$ years $(\mathrm{r}=0.75, \mathrm{p}<0.001)$ and 24 years $(\mathrm{r}=0.69, \mathrm{p}=0.003)$. At 24 years, a positive bronchodilator response was observed in almost a quarter (23.5\%) of subjects [28]. The importance of early respiratory support and its long-term consequences were highlighted in a keynote lecture by Dr Roehr who, in a presentation in the Paediatric Year in Review session, reflected on the origins of noninvasive respiratory support of neonates and presented the most recent trials of using noninvasive respiratory support in infants and young children. Acknowledging that nasal CPAP remains the gold standard of noninvasive respiratory support in neonatal and paediatric intensive care units, the physiology of high-flow nasal cannula was reviewed and recent trials on the application of nasal high-flow therapy throughout the delivery room, neonatal and paediatric intensive care units were discussed.

\section{Bronchoscopy}

Results of a survey of the use of bronchoscopy, performed in collaboration with the national representatives of 44 European countries, was reported during the Congress. The most frequent indication for diagnosis was chronic cough and stridor and, for acute use, foreign body aspiration [29]. By contrast, European expertise in bronchoscopic stenting of the narrowed bronchus is uncommon. Indeed, SERIO et al. [30], showed that bronchoscopic stenting is not straightforward. In seven children aged 0-13 years with left mainstem bronchus obstruction treated with expandable metallic balloon all children had major complications after a median (range) of $2.5(0.25-5)$ years.

\section{Cystic fibrosis}

The expanding adult CF population reflects the major improvements in the clinical care of children and young people with CF. This has led to an urgent need for the development of more adult centres, which must be combined with training more physicians and members of the multidisciplinary team to look after these complex patients. In 2015 the joint European Respiratory Society/European CF Society task force reported their recommendations for the future care of adults with CF [31]. The biggest hurdle will be the financial implications for healthcare services. Meanwhile, CF research is undoubtedly contributing to improvements in life expectancy. Use of the lung clearance index (LCI), which measures ventilation inhomogeneity, is becoming more common in CF clinics as it has been shown to be a useful marker of CF lung disease; it is also one of the more sensitive outcome measures available for clinical trials. Since longitudinal data are needed, a group presented a 5-year study of 80 stable Greek patients and found the mean annual change in LCI was $5 \%$ compared to $0.01 \%$ for FEV1 [32]. However, the change in LCI was not predicted by age, Pseudomonas status, or initial LCI and FEV1. Therefore, the clinical utility of measuring LCI at annual review remains to be seen. A larger study from North America followed 76 CF preschool children (aged 2.5-6 years) and 71 healthy controls measuring LCI six times over 1 year [33]. The researchers found that LCI was significantly worse in patients with a pulmonary exacerbation (mean 0.6 rise), whereas in healthy children it did not change with episodes of upper respiratory symptoms. With newborn screening we have become more aware of patients with CF-screen positive inconclusive diagnosis, CF patients with a borderline sweat test in the presence of none or one CFTR (CF transmembrane conductance regulator) gene mutation, or with a normal sweat test in the presence of two CFTR gene mutations; one of which has uncertain significance. Their clinical course is almost always milder than "classic CF" and this has been confirmed in a small Italian study where LCI in 17 children in this category were compared to $37 \mathrm{CF}$ patients and nine healthy controls; mean LCI was lower (i.e. better) than the CF patients (7.2 versus 9.7) and nonsignificantly higher than the controls [34]. It would be useful if a pulmonary exacerbation could be predicted, or at least detected early. Addressing this, a Dutch study assessed electronic home monitoring. 49 children were asked to use an electronic monitor (measuring FEV1 and a respiratory symptom questionnaire) three times a week [35]. Data were only analysable from 37 children, 28 of whom had at least one pulmonary exacerbation. The combined data were predictive of an exacerbation (93\% sensitivity and $89 \%$ specificity), but given the cost, issues of adherence and staff time for monitoring the data, it remains unclear whether this technology has any advantage from the usual process of parents contacting their CF team when their child has symptoms. A group from Israel studied the use of spirometry inspiratory capacity in 98 patients [36]. They found that once the inspiratory capacity reached $<60 \%$ predicted there was an accelerated decline in inspiratory capacity, accompanying a rise in residual volume (whilst total lung capacity remained in the normal range). The decline in inspiratory capacity did not correlate with a fall in FEV1 and the researchers suggested that their data: 1) indicated that air trapping may account for increasing breathlessness, and 2) that this measure added useful information to the usual parameters assessed by spirometry. Magnetic resonance imaging scanning 
is being studied to see whether it could replace computed tomography scanning with its inherent radiation burden. In a small Swiss-UK study of oxygen-enhanced magnetic resonance, it was found that functional lung imaging has the capability of assessing severity of lung disease, correlating with FEV1 and the computed tomography Brody score [37]. The images presented were stunning, but given the complexity, availability and cost it is unlikely to be a widely used clinical tool in the near future. Exercise is encouraged for all patients with CF but its uptake by children is highly variable, probably reflecting the sedentary lifestyle led by many healthy children. A UK study randomised 71 children into a control group receiving usual specialist $\mathrm{CF}$ care or an intervention group who also received weekly supervised exercise for 2 years [38]. No difference was seen in lung function (FEV1, LCI or peak oxygen uptake); however, the intervention group were fitter, with a significant difference in improvement seen in 10-min modified shuttle walking test. Given the burden of the intervention this is disappointing, but does not mean we should stop encouraging exercise. How many of the children continue to exercise long term once the supervision stops remains to be seen.

\section{Epidemiology}

Epidemiological data on primary ciliary dyskinesia (PCD), epigenetics and asthma were presented. The diagnosis of PCD needs standardisation, and easy and simple diagnostic tools are still required. The same group that recently published a validated symptom score (PICADAR) [39], presented a study showing that nasal nitric oxide to PICADAR had a high sensitivity and negative predictive value of $100 \%$ when used as a diagnostic tool [40]. As a novel diagnostic method, immunofluorescence labelling of ciliary proteins provides results within $48 \mathrm{~h}$, which is substantially faster than transmission electron microscopy. A study on immunofluorescence showed immunofluorescence as $57 \%$ sensitive and $100 \%$ specific compared to "gold standard" transmission electron microscopy [41]. The role of pre- and post-natal factors on respiratory health across the life course was an important theme. First, data from the Swedish National Registry, showed that maternal grandmother's smoking status is associated with an increased risk of early persistent asthma (OR 1.38, 95\% CI 1.15-1.65) [42]. Second, data were presented showing that reduced first and second trimester fetal size is associated with increased risk for asthma up to 10 years of age. Each z-score increase in first trimester size was associated with reduced risk for asthma at ages 5, 10 and 15 years [43]. Third, in a population-based birth cohort, maternal intake of sugar was positively associated with wheeze, total IgE and atopic asthma [44]. Finally, in a study analysing nine prospective European birth cohorts, elective caesarean section was associated with an increased risk of asthma [45]. The causal underlying mechanisms for these associations require further research. Predictors of future asthma in school age and adulthood continue to be of interest to researchers. One possibility is that multiple trigger wheeze (i.e. wheeze with and between viral colds) in preschool children identifies a group at increased risk of school age asthma. According to the data obtained from a longitudinal birth cohort study, children with severe wheeze and multiple trigger wheeze at preschool age had the greatest risk of doctor-diagnosed asthma at 8 years of age [46]. At each level of severity, multiple trigger wheeze potentiated the risk of asthma compared to having episodic viral wheeze [46]. In a study on the data from the Isle of Wight Birth Cohort, children still wheezing at 18 years were more likely to be atopic, female, diagnosed as asthmatic at 10 years of age, and have higher levels of bronchial hyperreactivity at 10 years of age [47]. The Perth Infant Asthma follow-up study showed lung function from soon after birth was predictive of the FEV1/ forced vital capacity ratio in young adults, suggesting that chronic obstructive pulmonary disease may have origins in the antenatal developing lung. Breastfeeding was protective against reduced FEV1/forced vital capacity and should continue to be promoted [48].

\section{Physiology and sleep}

Spirometry, static lung volumes, gas transfer measurements and polysomnography (PSG) remain the mainstay of respiratory and sleep medicine. However, there is a quiet revolution of both old and newer tests emerging into clinical practice. Nowhere is this more evident than in rare diseases, a field in which we are constantly challenged to deliver better answers. The research presented at the 2016 ERS Congress demonstrates that we continue to ask which test. Duchenne muscular dystrophy affects one in 3500 boys, is incurable and leads to early mortality in the late $20 \mathrm{~s}$ as a result of respiratory failure. Disease modifying treatments are only just emerging and therefore management remains supportive. Nocturnal hypoventilation represents a critical turning point in the progression of Duchenne muscular dystrophy and, although PSG testing remains the gold standard for its identification, overnight oximetry is recommended as a screening test by the British Thoracic Society [49]. BAKer et al. [50] compared overnight oximetry and transcutaneous oxicapnography as a sensitive screening tool. They demonstrated that oximetry alone was insensitive to elevated carbon dioxide and that the use of the combination of oxygen and carbon dioxide monitoring conferred the highest sensitivity to nocturnal hypoventilation. Further work is needed to replicate these findings and to compare against full PSG outcomes, but if 
confirmed would offer low-cost, home-based opportunities to improve the screening of patients with Duchenne muscular dystrophy.

The impact of PCD on lung function and the natural history of disease progression on lung function outcomes are not well understood, hampering our ability to manage disease progression. HALBEISEN et al. [51] collated over 1400 spirometry results from 276 children and young people with PCD from the iPCD cohort. Spirometry outcomes in individuals with PCD were lower than the norm as derived from the Global Lung Function Initiative and significantly declined over time with FEV1 decreasing by -0.07 Z-scores per year and, while this represents a relatively modest function, impact would lead to clinically relevant reductions ( $>0.5 \mathrm{z}$-score) over childhood. Clearly, the challenge of identifying clinical characteristics associated with accelerated decline and therefore potentially actionable management targets remain. In contrast to CF lung disease, LCI does not appear to be sensitive to PCD lung disease [52] and until the question of which test proves the most clinical useful information is resolved, spirometry continues to be the gold standard.

The prognosis for infants born with congenital diaphragmatic hernia have dramatically improved over the past 60-70 years such that survival has now been reported to be as high as $90 \%$ in some centres [53]. This increased survival is often at the cost of significant and persistent respiratory morbidity. RoHDIN et al. [54] reported the novel application of single positron emission computed tomography imaging to assess ventilation perfusion in 23 infants with congenital diaphragmatic hernia in the first year of life. Not surprisingly, ventilation/perfusion varied widely amongst infants and was most affected in infants requiring patch surgery and/or extracorporeal membrane oxygenation. However, ventilation/perfusion function did not match the clinical course in all cases with some infants highlighting the potential benefits for this form of functional assessment to assist in the long-term management of individual with congenital diaphragmatic hernia.

\section{Asthma mechanisms}

Although asthma is highly prevalent and has been extensively studied, novel methodologies are needed to determine the exact role of inflammation and remodelling in this complex clinical/pathological entity [55]. At the 2016 Congress there was a significant emphasis on the role of prenatal period factors on asthma development. Starting with the amniotic fluid, a Dutch-Italian group analysed the amniotic fluid of 142 infants at birth by the untargeted approach of metabolomics (mass spectrometry and liquid chromatography) and was able to retrospectively discriminate infants who developed recurrent wheezing during the first year of life from those who did not develop wheezing. The results suggested early oxidative stress and impaired methylation as prenatal pathogenic mechanisms of recurrent wheezing [56]. An Australian study assessed the effect of prenatal hypoxia-induced growth restriction on lung structure in adult rats [57]. Based on the observation in humans that intra-uterine growth restriction is associated with asthma in childhood and adulthood and the assumption that this growth restriction is due to fetal hypoxia, the researchers temporarily housed pregnant Sprague Dawley rats under hypoxic conditions (11.5\% oxygen). These hypoxic conditions were in the phase that the airways develop, the pseudoglandular-canicular phase from gestational days 13-20, rats were then returned to normoxia until the end of gestation at days 21-23. The rats indeed had lower weight at birth, but the weight difference disappeared by 7 weeks. In utero growth restriction unexpectedly had no impact on mean airway measurements or lung structure, but there was a more heterogeneous distribution of airway lumen calibre and an increased number of lung macrophages. Whether these changes reflect a pro- or anti-inflammatory milieu remains to be established. Moving to post-natal factors, a retrospective review of 109 children with severe therapy-resistant asthma who underwent bronchoscopies for evaluation of their asthma found that $20 \%$ had a positive bronchoalveolar lavage bacterial culture. A positive culture was associated with a higher maintenance dose of inhaled steroid, lower FEV1 and higher bronchoalveolar lavage neutrophils [58]. Thus, children with severe therapy resistant asthma and bacterial infection or colonisation seem to have more severe disease.

\section{Inhaled pollutants}

The role of the environment in the development of asthma has long been recognised. In a RCT of 150 children with persistent asthma, led by a nursing group from Baltimore (MD, USA), the IgE levels to mouse and cockroach were measured and related to neighbourhoods with the highest quartile of reported dirty alleys/streets compared to other neighbourhoods [59]. Furthermore, mean perceived neighbourhood stress scores were related to dirty alley neighbourhood status. Higher IgE to mouse (59\% versus $42 \%$ ), but not cockroach allergen ( $46 \%$ versus $40 \%$ ), was significantly associated with living in a dirty neighbourhood. An emerging topic that was extensively covered during the Congress was use of e-cigarettes. The sale of e-cigarettes is increasing exponentially and e-cigarettes draw on themes of the defunct advertising of conventional cigarettes. Perhaps this would not be of concern if e-cigarettes were a highly effective non-toxic way of encouraging conventional cigarette smokers to stop. However, whether 
substantial persistent reduction in cigarettes smoked is achieved in dual smokers remains unclear since significant conflict of interests occur in over one-third of published studies, and to date no overall conclusion on the safety of e-cigarettes can be drawn $[60,61]$.

\section{References}

1 Craven V, Cuthbertson L, Elphick E, et al. The impact of a persistent bacterial bronchitis on the pulmonary microbiome of children. Eur Respir J 2016; 48: Suppl. 60, OA4982.

2 Masekela R, Volsoo S, Green R, et al. Microbiota in children with HIV-associated bronchiectasis. Eur Respir J 2016; 48: Suppl. 60, OA4988.

3 Grammeniatis V, Papadopoulos M, Boutopoulou B, et al. How much protracted is protracted bacterial bronchitis (PBB)? Eur Respir J 2016; 48: Suppl. 60, OA1497.

4 Chih-Yung $\mathrm{C}$, Lin G, Cheng M-L, et al. Metabolomic analysis of infectious parapneumonic effusions reveals biomarkers for management of children with Streptococcus pneumoniae pneumonia. Eur Respir J 2016; 48: Suppl. 60, OA4984.

5 Kepreotes E, Whitehead B, Attia J, et al. A randomized controlled trial examining high-flow oxygen in the management of infants with moderate bronchiolitis. Eur Respir J 2016; 48: Suppl. 60, OA4983.

6 Heikkilä P, Korppi M. High-flow oxygen therapy is more effective and less expensive for bronchiolitis than standard low-flow oxygen therapy: a decision analysis. Eur Respir J 2016; 48: Suppl. 60, PA1286.

7 Mecklin M, Heikkilä P, Korppi M. Risk factors for intensive care and respiratory support among infants with bronchiolitis. Eur Respir J 2016; 48: Suppl. 60, PA1595.

8 Unger S, Halliday C, Steve Cunningham S. Blood gas analysis in acute bronchiolitis: who and when? Eur Respir J 2016; 48: Suppl. 60, PA1596.

9 Mayfield S, Bogossian F, O'Malley L, et al. High-flow nasal cannula oxygen therapy for infants with bronchiolitis: pilot study. J Paediatr Child Health 2014; 50: 373-378.

10 Poh M, Fonceca A, Kicic A, et al. Abortive replication and reactivation in vitro respiratory syncytial virus (RSV) infection in palivizumab-treated HeLa cells. Eur Respir J 2016; 48: Suppl. 60, PA2610.

11 Veras TH, Bertelli LJ, Zemczak N, et al. Necrotizing pneumonia in children: experience in a pediatric tertiary care hospital. Eur Respir J 2016; 48: Suppl. 60, PA1280.

12 Turner S, Spiteri D, Miller D, et al. Nasal airway epithelial cells cytokine responses in children stratified by asthma and atopy. Eur Respir J 2016; 48: Suppl. 60, OA4986.

13 Hooper SB, Te Pas AB, Kitchen MJ. Respiratory transition in the newborn: a three-phase process. Arch Dis Child Fetal Neonatal Ed 2016; 101: F266-F271.

14 Jobe AH, Hillman N, Polglase G, et al. Injury and inflammation from resuscitation of the preterm infant. Neonatology 2008; 94: 190-196.

15 Harris C, Zivanovic S, Alcazar-Paris M, et al. Postnatal corticosteroids and lung function at school age in very prematurely born infants. Eur Respir J 2016; 48: Suppl. 60, OA247.

16 Kamlin CO, Schmoelzer G, Dawson J, et al. A randomized trial of oropharyngeal airways to assist stabilization of preterm infants in the delivery room. Eur Respir J 2016; 48: Suppl. 60, OA242.

17 Pahuja A, Murthy V, Bhat P, et al. Tidal volumes and ETCO2 levels during resuscitation and prematurely born infants' outcomes. Eur Respir J 2016; 48: Suppl. 60, PA1290.

18 van Vonderen JJ, Roest AA, Siew ML, et al. Measuring physiological changes during the transition to life after birth. Neonatology 2014; 105: 230-242.

19 Fischer HS, Buhrer C. Avoiding endotracheal ventilation to prevent bronchopulmonary dysplasia: a meta-analysis Pediatrics 2013; 132: e1351-e1360.

20 Meyer MP, Hou D, Ishrar NN, et al. Initial respiratory support with cold, dry gas versus heated humidified gas and admission temperature of preterm infants. J Pediatr 2015; 166: 245-250.

21 Shetty S, Greenough A. Review finds insufficient evidence to support the routine use of heated, humidified high-flow nasal cannula use in neonates. Acta Paediatr 2014; 103: 898-903.

22 Mazmanyan P, Darakchyan M, Moylan M, et al. Nasal high flow reduces minute ventilation in neonates. Eur Respir J 2016; 48: Suppl. 60, PA1294.

23 Zivanovic S, Bresesti I, Roehr C. Survey on the use and weaning of non-invasive ventilation among UK tertiary neonatal units. Eur Respir J 2016; 48: Suppl. 60, PA1295.

24 Shetty S, Sundaresan A, Hunt K, et al. Changes in use of heated humidified high flow nasal cannula oxygen. Eur Respir J 2016; 48: Suppl. 60, PA1296.

25 Winter M, Hutchings F, Hilliard T, et al. Use of heated humidified high flow nasal cannula therapy in a tertiary children's hospital. Eur Respir J 2016; 48: Suppl. 60, PA1297.

26 Bentsen M, Markestad T, Halvorsen T, et al. Predicting development of bronchopulmonary dysplasia in extremely preterm neonates using flow data from a mechanical ventilator. Eur Respir J 2016; 48: Suppl. 60, PA1292.

27 Moschino L, Carraro S, Zanconato S, et al. Evaluation of lung function in BPD survivors from infancy to adulthood: the Padova BPD study. Eur Respir J 2016; 48: Suppl. 60, OA241.

28 Filippone M, Sartor M, Zacchello F, et al. Flow limitation in infants with bronchopulmonary dysplasia and respiratory function at school age. Lancet 2003; 361: 753-754.

29 Yu Y, Schramm D, Snijders D, et al. Paediatric flexible and rigid bronchoscopy in European centres: state of the art. Eur Respir J 2016; 48: Suppl. 60, OA1495.

30 Serio P, Nenna R, Di Maurizio M, et al. Permanent bronchial stents in left mainsteam bronchus: closed follow up and low-risk interventions to manage potential fatal complications. Eur Respir J 2016; 48: Suppl. 60, OA1497.

31 Elborn JS, Bell SC, Madge SL, et al. Report of the European Respiratory Society/European Cystic Fibrosis Society task force on the care of adults with cystic fibrosis. Eur Respir J 2016; 47: 420-428.

32 Avramidou V, Hatziagorou E, Terzi D, et al. Annual change of LCI among patients with cystic fibrosis. Eur Respir J 2016; 48: Suppl. 60, OA1488.

33 Stanojevic S, Jensen R, Webser $\mathrm{H}$, et al. Tracking pulmonary exacerbations in preschool children using the lung clearance index. Eur Respir J 2016; 48: Suppl. 60, OA1490. 
34 Andreatta E, Volpi S, Lubrano L, et al. Lung clearance index in young children with atypical CF. Eur Respir J 2016; 48: Suppl. 60, OA1489.

35 Dompeling E, Van Horck M, Winkens B, et al. Early detection of pulmonary exacerbations in children with cystic fibrosis by electronic home monitoring of symptoms and lung function. Eur Respir J 2016; 48: Suppl. 60, OA1491.

36 Vilozni D, Dagan A, Lavie M, et al. Inspiratory capacity in cystic fibrosis: a silent predictor of lung deterioration. Eur Respir J 2016; 48: Suppl. 60, OA1487.

37 Martini K, Benden C, Parker G, et al. Oxygen-enhanced MR (OE-MR): correlation of CT Brody score in cystic fibrosis patients. Eur Respir J 2016; 48: Suppl. 60, OA1492.

38 Ledger S, Wade A, Douglas H, et al. Interim results of INSPIRE-CF: a 24 month RCT evaluating effects of weekly supervised exercise in children with CF. Eur Respir J 2016; 48: Suppl. 60, OA1493.

39 Behan L, Dimitrov BD, Kuehni CE, et al. PICADAR: a diagnostic predictive tool for primary ciliary dyskinesia. Eur Respir J 2016; 47: 1103-1112.

40 Collins S, Behan L, Gove K, et al. Effective patient selection for PCD diagnostics; the PICADAR score with nasal nitric oxide. Eur Respir J 2016; 48: Suppl. 60, PA3124.

41 Coles J, Goggin P, Thompson J, et al. Introducing immunofluorescence as a diagnostic tool for primary ciliary dyskinesia. Eur Respir J 2016; 48: Suppl. 60, PA3125.

42 Braback L, Lodge C, Lowe A, et al. Childhood asthma in relation to maternal and paternal preconceptional nicotine exposures. Eur Respir J 2016; 48: Suppl. 60, OA3301.

43 Turner S, Fielding S, Devereux G. Fetal origins of persistent childhood asthma. Eur Respir J 2016; 48: Suppl. 60, OA3302.

44 Bedard A, Northstone K, Henderson J, et al. Maternal sugar intake during pregnancy and respiratory and atopic outcomes in childhood. Eur Respir J 2016; 48: Suppl. 60, OA3303.

45 Rusconi F, Zugna D, Annesi-Maesano I, et al. Mode of delivery and asthma at school age in nine European birth cohorts. Eur Respir J 2016; 48: Suppl. 60, OA3299.

46 Goksör E, Alm B, Strömlind-Celind F, et al. Both severity and triggers of preschool wheeze increase the risk of asthma at school age. Eur Respir J 2016; 48: Suppl. 60, PA1309.

47 Kurukulaaratchy RJ, Hodgekiss C, Roberts G, et al. Factors determining persistence of childhood persistent wheeze into young adulthood. Eur Respir J 2016; 48: Suppl. 60, PA3133.

48 Owens L, Laing IA, Zhang G, et al. Can risk factors for COPD be traced back to infancy? The Perth infant asthma follow-up study. Eur Respir J 2016; 48: Suppl. 60, OA3305.

49 Hull J, Aniapravan R, Chan E, et al. British Thoracic Society guideline for respiratory management of children with neuromuscular weakness. Thorax 2012; 67: Suppl 1, i1-i40.

50 Baker R. Gibson N, Davies P. Oximetry screening alone is not sufficient to identify nocturnal hypoventilation in Duchenne muscular dystrophy. Eur Respir J 2016; 48: Suppl. 60, PA4350.

51 Halbeisen F. Goutaki M. Maurer E, et al. Lung growth in children and young adults with primary ciliary dyskinesia (PCD): an iPCD cohort study. Eur Respir J 2016; 48: Suppl. 60, PA375.

52 Irving SJ, Ives A, Davies G, et al. Lung clearance index and high-resolution computed tomography scores in primary ciliary dyskinesia. Am J Respir Crit Care Med 2013; 188: 545-549.

53 Javid PJ, Jaksic T, Skarsgard ED, et al. Survival rate in congenital diaphragmatic hernia: the experience of the Canadian Neonatal Network. J Pediatr Surg 2004; 39: 657-660.

54 Rohdin M. Radell P. Sanchez Crespo A, et al. Post-operative lung function impairment in infants with congenital diaphragmatic hernia. Eur Respir J 2016; 48: Suppl. 60, PA1218.

55 Saglani S, Lloyd CM. Novel concepts in airway inflammation and remodelling in asthma. Eur Respir J 2015; 46: 1796-1804.

56 Carraro S, Giordano G, Pirillo P, et al. Metabolomics profile of amniotic fluid and early recurrent wheezing. Eur Respir J 2016; 48: Suppl. 60, OA 4799.

57 Wang K, Morton J, Davidge S, et al. Effect of prenatal hypoxia-induced growth restriction on lung structure in adult rats. Eur Respir J 2016; 48: Suppl. 60, OA4800.

58 Cook C, Bush A, Saglani S, et al. Higher doses of inhaled steroid are associated with bacterial bronchitis in children with severe therapy resistant asthma (STRA). Eur Respir J 2016; 48: Suppl. 60, OA4802.

59 Lewis-Land C, Bollinger MB, Tsoukleris M, et al. Association of neighbourhood hygiene (dirty streets and alleys) on urban children with asthma. Eur Respir J 2016; 48: Suppl. 60, OA4805.

60 Pisinger C, Dossing M. A systematic review of health effects of electronic cigarettes. Prev Med 2014; 69: 248-260.

61 Pisinger C. Epidemiology of e-cigarette use. Health effects of e-cig.. Eur Respir J 2016; 48: Suppl. 60, PA2978. 